\title{
Rates of Condom use among HIV Positive Patients on ART in Nasarawa Eggon North Central Nigeria
}

\author{
Joseph E Enegela*, Ochanya Iyaji Paul, Olanrewaju Olaiya, Edward Ugba, Patrick Okoh, Olufunmilayo \\ Ogundeko, Ayodele Fagbemi, Oladipo Akinmade, Iko Ibanga and Amana Effiong \\ Pro-Health International, IPSAN project, Nigeria \\ *Corresponding author: Joseph E Enegela, Pro-Health International, IPSAN project, Nigeria
}

\begin{abstract}
ARTICLE INFO
Received: 幽 June 03, 2019

Published: 幽 June 11, 2019

Citation: Joseph E Enegela, Ochanya Iyaji Paul, Olanrewaju Olaiya, Edward Ugba, Patrick Okoh, Olufunmilayo Ogundeko, Ayodele Fagbemi, Oladipo Akinmade, Iko Ibanga, Amana Effiong. Rates of Condom use among HIV Positive Patients on ART in Nasarawa Eggon North Central Nigeria. Biomed J Sci \& Tech Res 18(5)-2019. BJSTR. MS.ID.003201.
\end{abstract}

Keywords: ART; Condom, HIV

\begin{abstract}
Introduction: Consistent condom use still remains a key strategy in HIV prevention. Studies have demonstrated declining condom use among HIV positive patients on ART. There is paucity of such information among HIV positive individuals on ART in Nigeria. We sought to find the rates and associated factors for condom use among a cohort of PLHIV on ART in Nigeria.
\end{abstract}

Methods: A cross sectional review of PLHIV on ART was carried out in an ART treatment facility. Trained clinic staff administered a checklist to adult patients who had been on ART for a minimum of 9 months. Information was collected on age, sex, marital status, number of sexual partners, condom use and occurrence of sexually transmitted infection.

Results: Of the 282 respondents; average age was 35 years. Forty four percent (44\%) never used while $25 \%$ used condoms consistently in the previous 3 months. Single (OR: 7.23, CI: 2.999-17.446, p= 0.000) and widowed (OR: 3.76, CI-1.179-12.04, $\mathrm{p}=0.026$ ) respondents were more likely to use condom always or sometimes. Male respondents were almost twice as likely to use condoms always and sometimes (OR: 1.74, CI-0.988-3.078, $\mathrm{p}=0.055$ ). There was no significant association between condom use and history of STI (OR: 0.74, CI- $0.444-1.239, \mathrm{p}=0.254$ ), or number of sexual partners (OR: 0.93, CI-0.427-2.01, $\mathrm{p}=0.848$ ).

Conclusion: Rates of condom use was low particularly among females and married patients on ART. Program and clinic managers should aggressively target females and married couples with varied and appropriate prevention messaging to improve coverage.

\section{Introduction}

The global picture of the HIV epidemic has continued to show evidence of impact of the social, biomedical and behavioral HIV prevention strategies [1], with new HIV infections dropping to 2.1 million in 2015 [2] from 5 million in 2001 [3]. In Nigeria, the number of new infections was reported to have reduced by about $24 \%$ in the same period [2]. Much of this progress however seems to have happened in the period prior to 2010 as between that year and 2015, only about 100,000 new HIV infections were reported [2]. Although there are several others, some of the important factors that could have affected the slowing of this progress include the stall in condom provision and use with an over 50\% condom gap in sub-Saharan Africa [1]; persistent socio-cultural barriers

including gender inequality, refusal to use in marriage, and vaginal douching $[4,5]$, all which predate the gap in provision of condoms. Condom use has been severally demonstrated to contribute significantly to attenuating sexual transmission of HIV and is therefore an important factor in the control and eradication of the virus. Condom use was shown to reduce transmission risk 20 fold in a study that quantified per act risk of transmission on a basis of various risk factors [6] while in another study of 17,450 sexually active individuals in Uganda; condom use significantly reduced the incidence of HIV infection [7].

Furthermore, a recent meta-analysis on per-act risk of HIV transmission demonstrated a $99.2 \%$ attenuation of HIV acquisition 
risk when there is a dual use of condom and ART in the HIV positive individual [8]. While some studies have shown a positive adjustment in sexual risk behavior after commencing ART [9], others have shown a condom fatigue and consequent negative adjustment in risky sexual behavior over the long term $[10,11]$. In Nigeria, 38\% of all sexually active respondents in a national reproductive health survey had ever used male condoms, out of which $54 \%$ are current users (defined as condom use in the preceding 12 months with the proportion of females respondents being less than their male counterparts) [12]. Information on condom use rate among patients on ART in Nigeria is sparse and varied with no clear pattern. Reports from South Western Nigeria found a very low condom use rate among HAART naïve $(13 \%)$ and experienced (16\%) clients respectively, with consistent use being more likely among females [13]; a condom use rate of $75.9 \%$ with a more likely prevalence among males, singles and those with formal education [14] and a third reported a condom use rate of $53.8 \%$ among patients on ART, 12 months after commencing treatment, with married clients being more likely to use condoms [15]. These coupled with the few number of studies, the variability in factors thought to contribute to higher condom use rates and the differences in HIV/AIDS prevalence across the country further indicates that studies are required in this area, especially from population not previously studied in this regards. In this study, we sought to examine the rate of condom use and associated factors among a cohort of HIV positive patients on ART.

\section{Methods}

\section{Study Location}

Nasarawa Eggon General hospital, based in Nasarawa Eggon Local Government Area, is a secondary health facility that has been providing care for people living with HIV since 2004. It is located in Nasarawa, one of the six states in the north central region of Nigeria with an HIV prevalence of 8.1\% [12]. As a local government-level facility, it has a catchment of about 148,402 population [16] and an additional unknown transit population as the town sits on a major transit corridor between the north and the south of the country. With funding from the USG/PEPFAR through the Centers for Diseases Control and Prevention, it is the only facility providing comprehensive HIV/AIDS care, prevention and treatment services in the local government area. Patients also receive condoms free of charge both within the community through community-based organizations and from designated health care workers within the facility.

\section{Study Sample and Procedure}

This was cross sectional study of 392 randomly selected patients from a total 995 on antiretroviral therapy that visited the hospital in July 2015. These are HIV positive patients of either sex who are a minimum of sixteen years of age and had been on Antiretroviral therapy for at least 9 months at the time of the review. There was no discrimination on basis of patient regimen type. The review included evaluation of clinical management histories as well as immunological and virologic laboratory results. Prior to the commencement of the review, patients' care teams were trained on the process and the administration of select tools. In addition, eligible clients were administered a checklist to assess their level of treatment adherence, adherence to lifestyle changes, as well as evaluation of the social support structure available to them. The checklist also collected information on age and sex of respondents, marital status, number of sexual partners, history of sexually transmitted infection in the preceding 12 months and history of condom use in the preceding 3 months.

We defined condom use as the use of either male or female condom by either partner during sexual intercourse in the preceding 3 months. Condom use responses were graded into those who "always" correctly and consistently used condom during all sexual encounters, those who "never" used, and those who use "some of the times". Patients who were not sexually active during the period were categorized as "not applicable". We ascertained history of STI by asking history of genitourinary discharge, genital ulcers, history of STI diagnosis and/or treatment; patients were required to answer yes or no to the presence of any or all the symptoms. Marital status of patients where categorized into married, divorced or separated, widowed and single. Trained adherence counselors and nurses administered the checklist to all eligible patients. The sample size was determined using a 99\% confidence level assuming 0.5 proportion. The sample was then drawn randomly from the pool of administered checklist.

\section{Data Analysis}

Data from the checklist was transferred into a Microsoft Excel for coding, anonymization and cleaning. Further analysis was done using STATA version 14, StataCorp. 2015. Stata Statistical Software: Release 14. College Station, TX: StataCorp LP. Sociodemographic characteristics were expressed in simple percentages while Pearson's Chi square test was used to test for association between some of the demographic information and condom use rate in a bivariate analysis while a multivariate ordinal logistic regression was used to test the strength and direction of the association. Statistically significant association was accepted at $\mathrm{p}<0.05$ and $95 \%$ confidence interval (CI). Ethical clearance for the review was received from the Nigerian National Health Research Ethics Committee under a non-research determination exemption for public health activities. NHREC approval number NHREC/01/01/2007-14/10/2015.

\section{Results}

After correcting for missing data, inappropriate and declined responses, 282 were included for the analysis and a further 35 respondents who did not have any sexual partner were excluded from the regression analysis as they were unlikely to use condoms. Table 1 describes the population characteristics; the average age in the group was 35 years with a median of 33 (SD 9.59). Most of 
the respondents $(45 \% ; 128)$ were between the ages of 25 and 34 , while $20 \%$ were 45 years and above (Figure 1). Approximately $67 \%$ of the respondents were females, $72 \%$ (202) were married while $13 \%$ (36) and 10\% (28) were single and widowed respectively. Forty-four percent of the respondents never use condom during sexual intercourse, while 31\% (86) and 25\% (69) use condoms "sometimes" or "always" respectively. Furthermore, most respondents $(77 \%$; 128) had only one sexual partner while only $10 \%$ had multiple sexual partners. Sixty two percent (176) had no history of sexually transmitted infections. On marital status, thirty eight percent (38\%) of divorced/separated respondents, $42 \%$ of the married, $11 \%$ and $18 \%$ of the single and widowed respondents respectively never used condoms during sexual intercourse in the previous three months.

\section{Figure 1: Age distribution of respondents (yrs) $=15-24=25-34=35-44=45+$}
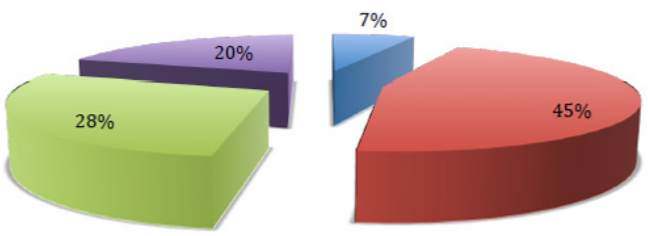

Figure 1.

Table 1: Population Characteristics.

\begin{tabular}{|c|c|c|}
\hline Characteristics & Frequency & Percentage \\
\hline \multicolumn{3}{|c|}{ Condom Use } \\
\hline Never & 92 & 44 \\
\hline Sometimes & 86 & 31 \\
\hline Always & 69 & 25 \\
\hline \multicolumn{3}{|c|}{ Age Group } \\
\hline
\end{tabular}

\begin{tabular}{|c|c|c|}
\hline $15-24$ & 19 & 7 \\
\hline $25-34$ & 128 & 45 \\
\hline $35-44$ & 79 & 28 \\
\hline $45+$ & 56 & 20 \\
\hline \multicolumn{3}{|c|}{ Sex } \\
\hline Female & 190 & 67 \\
\hline Male & 92 & 33 \\
\hline \multicolumn{3}{|c|}{ Marital Status } \\
\hline Divorced & 16 & 5 \\
\hline Married & 202 & 72 \\
\hline Single & 36 & 13 \\
\hline Widowed & 28 & 10 \\
\hline \multicolumn{3}{|c|}{ Number of Sexual Partners } \\
\hline No Sexual Partner & 35 & 13 \\
\hline One Sexual Partner & 218 & 77 \\
\hline Multiple Partners & 29 & 10 \\
\hline \multicolumn{3}{|c|}{ STI } \\
\hline No & 176 & 62 \\
\hline Yes & 106 & 38 \\
\hline
\end{tabular}

In a bivariate analysis (Table 2), we found a significant relationship [ $p=0.001]$ between marital status and condom use. There was no significant relationship between condom use and age $(\mathrm{p}=0.837)$. On further analysis using a multivariate ordinal regression model (Table 3) we found that single (OR: 7.23, CI: 2.999-17.446, $\mathrm{p}=0.000$ ) and widowed (OR: 3.76, CI-1.179-12.04, $\mathrm{p}=0.026$ ) respondents were more likely to use condom "always" or "sometimes" when compared with married couples. Male respondents were almost twice as likely to use condoms always and sometimes as their female counterparts (OR: 1.74, CI-0.988$3.078, p=0.055$ ). No significant association was found in condom use between respondents who had history of STI and those who didn't (OR: 0.74, CI-0.444-1.239, p=0.254), or between those who had multiple sexual partners and those with one sexual partner (OR: 0.93, CI-0.427-2.01, $\mathrm{p}=0.848$ ).

Table 2: Bivariate Relationship between characteristics and condom use.

\begin{tabular}{|c|c|c|c|c|}
\hline \multicolumn{4}{|c|}{ Condom Use } & \multirow{2}{*}{ p-value } \\
\hline & Never & Sometimes & Always & \\
\hline \multicolumn{5}{|c|}{ Sex } \\
\hline Female & $40.5 \%$ & $32.9 \%$ & $26.6 \%$ & \multirow{2}{*}{0.369} \\
\hline Male & $031.5 \%$ & $38.2 \%$ & $30.3 \%$ & \\
\hline \multicolumn{5}{|c|}{ Age } \\
\hline $15-24$ & $47.4 \%$ & $31.6 \%$ & $21.0 \%$ & \multirow{4}{*}{0.872} \\
\hline $25-34$ & $40.6 \%$ & $30.5 \%$ & $28.9 \%$ & \\
\hline $35-44$ & $48.1 \%$ & $31.6 \%$ & $20.3 \%$ & \\
\hline $45+$ & $46.4 \%$ & $30.4 \%$ & $23.2 \%$ & \\
\hline \multicolumn{5}{|c|}{ Number of Sexual Partners } \\
\hline One & $39.0 \%$ & $33.5 \%$ & $27.5 \%$ & \multirow{2}{*}{0.276} \\
\hline Multiple & $24.1 \%$ & $44.8 \%$ & $31.0 \%$ & \\
\hline
\end{tabular}




\begin{tabular}{|c|c|c|c|c|}
\hline \multicolumn{5}{|c|}{ Marital Status } \\
\hline Divorced & $38.4 \%$ & $30.8 \%$ & $30.8 \%$ & \multirow{4}{*}{0.001} \\
\hline Married & $41.8 \%$ & $36.2 \%$ & $22.0 \%$ & \\
\hline Single & $11.1 \%$ & $25.9 \%$ & $63.0 \%$ & \\
\hline Widowed & $18.2 \%$ & $36.4 \%$ & $45.4 \%$ & \\
\hline \multicolumn{5}{|c|}{ STI } \\
\hline Yes & $36.2 \%$ & $33.5 \%$ & $30.3 \%$ & \multirow{2}{*}{0.586} \\
\hline No & $38.9 \%$ & $36.8 \%$ & $24.2 \%$ & \\
\hline
\end{tabular}

Table 3: Multivariate Ordinal Logistic Regression Model.

\begin{tabular}{|c|c|c|c|c|}
\hline \multirow{2}{*}{ Variables } & \multirow{2}{*}{ Odd Ratio } & \multirow{2}{*}{ p-value } & \multicolumn{2}{|c|}{ Confidence Interval } \\
\hline & & & Low & High \\
\hline \multicolumn{5}{|c|}{ Sex } \\
\hline Male & 1.74 & 0.055 & 0.988 & 3.078 \\
\hline Female & Ref & Ref & Ref & Ref \\
\hline \multicolumn{5}{|c|}{ Age } \\
\hline $15-24$ & Ref & Ref & Ref & Ref \\
\hline $25-34$ & 1.46 & 0.468 & 0.527 & 4.024 \\
\hline $35-44$ & 0.85 & 0.765 & 0.289 & 2.492 \\
\hline $45+$ & 1.23 & 0.727 & 0.38 & 3.996 \\
\hline \multicolumn{5}{|c|}{ No of Sexual Partner } \\
\hline One & 0.93 & 0.848 & 0.427 & 2.01 \\
\hline Multiple & Ref & Ref & Ref & Ref \\
\hline \multicolumn{5}{|c|}{ Marital Status } \\
\hline Divorced & 1.50 & 0.460 & 0.51 & 4.424 \\
\hline Married & Ref & Ref & Ref & Ref \\
\hline Single & 7.23 & 0.000 & 2.999 & 17.446 \\
\hline Widowed & 3.76 & 0.026 & 1.174 & 12.04 \\
\hline \multicolumn{5}{|c|}{ STI } \\
\hline Yes & 0.74 & 0.254 & 0.444 & 1.239 \\
\hline No & Ref & Ref & Ref & Ref \\
\hline
\end{tabular}

\section{Discussion}

Despite the proven effect of ART as a strategy in HIV prevention, the use of condoms has continued to be an important component of preventing HIV and other STIs and therefore remains integral in the combination prevention [1] strategy. Only $25 \%$ of the respondents in our study always used and 44\% never used condoms during sexual intercourse. This is at variance with a study from western Nigeria where consistent and correct use of condoms was seen in $75 \%$ of the study participants [14]. A second study from Western Nigeria went further to demonstrate a change in condom use rates between a pre ART rate of $14.0 \%$ and a post ART rate of $43.3 \%$. [15] It is however consistent with other studies including one from South Eastern Nigeria that demonstrated low rates of condom use [17-19]. These reported low rates of consistent use of condoms are important when considered against the backdrop of poor adherence, which eventually negates the preventive effect of ART. Although we did not evaluate the effect of condom availability on its use or lack of, it is instructive to state that even when individuals have the means to purchase condoms, studies have demonstrated issues like low risk perception and lack of motivation as factors that contribute to non-usage [20]. A second factor may be the effect of human resource challenges on the ability of health care workers to continually deliver care; including ART scale up and accurate condom messaging to PLHIV attending clinics [21,22]. Our analysis also showed that men were twice as likely to use condom always or sometimes. This may be due to male dominance in relationships in Nigeria, lower likelihood for women to negotiate safe sexual practices [23,24], coupled with poor uptake of female condoms occasioned by unavailability, cost and difficulty in insertion $[25,26]$. We are aware that female condoms are however not popular in the target facility due to limited supplies and a general apathy among health workers towards female condom counseling.

Single and widowed respondents showed very high likelihood of using condoms sometimes or always when compared to married couples. The observation was similar to other studies that demonstrated low rates of condom use among married couples [27]. 
This may be due to a reduced risk perception seeing that they are in a 'stable' relationship or with someone they trust; with or without concordance, and a lack of disclosure may also be a significant factor as observed in some studies [28,29]. Furthermore, as patients get healthier, their desire to have children has been shown to invariably influence condom use $[29,30]$. It could also be argued that the single and widowed do not have stable relationships, and are therefore more mindful of getting infected with 'other' subtypes of the virus or STIs. It could further be that the health care workers in the clinic have targeted single and widowed PLHIVs more with prevention and condom messages than they have married couples. All the above notwithstanding, a study has demonstrated patients in a marital union where more likely to use condom during sex [15]. Some of the limitations of the study included a possible role of culture and norms that may limit appropriate responses from female respondents. The study did not explore the reasons behind condom use choices but we acknowledge the importance of this added information in understanding individual reasons for choices; this may be the subject of future research.

\section{Conclusion}

Considering the central importance of the direct and indirect impact of condom messaging in the overall HIV prevention strategy, the need to promote higher condom use in our setting is nigh. Program managers must design better ways of keeping the appropriate condom messaging on the front burner of care and prevention services among HIV positive patients on ART with increased focus on females and married couples.

\section{Acknowledgement}

This publication was made possible with funding support from the HHS/Centers for Disease Control and Prevention (CDC) cooperative agreement number GH000929. The findings and conclusions in this manuscript are those of the authors and do not necessarily represent the views of the United States (U.S.) Centers for Disease Control and Prevention. Use of trade names is for identification only and does not imply endorsement by the U.S. Centers for Disease Control and Prevention or the U.S. Department of Health and Human Services. The authors will also like to thank Raphael Akpan and Aminu Yakubu of CDC for their valuable inputs during this work and completion of the manuscript.

\section{References}

1. (2010) Combination HIV Prevention: Tailoring and Coordinating Biomedical, Behavioural and Structural Strategies to Reduce New HIV Infections. UNAIDS.

2. (2016) Global AIDS update. UNAIDS.

3. (2002) Report on the Global HIV/AIDS Epidemic. UNAIDS.

4. Beksinska ME, Smit JA, Mantell JE (2012) Progress and challenges to male and female condom use in South Africa. Sexual Health 9(1): 51-58.

5. Oladele DA, Gab Okafor CV, Bamidele O, Olufela KO, Oluwatosin SE, et al. (2014) Pattern, challenges and correlates of condom us among Nigerians living with HIV infection. Asian Pacific Journal of Tropical Biomedicine 4(1): S198-S203.

6. Varghese B, Maher J, Paterman TA, Branson BM, Steketee RW (2002) Reducing the risk of sexual HIV transmission: Quantifying per-act risk of HIV on the basis of choice of partner, sex act and condom use. Sexual Transmitted disease 29(1): 38-43.

7. Ahmed S, Lutola T, Wawer M, Serwadda D, Sewankambo NK, et al. (2001) HIV incidence and sexually transmitted dieases prevalence associated with condom use: a population study in Rakai Uganda. AIDS 15(16): 2171-2179.

8. Patel P, Borkowf CB, Brooks JT, Lasry A, Lansky A, et al. (2014) Estimating per-act HIV transmission risk: A systematic review. AIDS 28 (10): 15091519.

9. McClelland RS, Graham SM, Richardson BA, Peshu N, Masese LN, et al. (2010) Treatment with Antiretroviral Therapy is Not Associated with Increased Sexual Risk Behaviour in Kenyan Female Sex Workers. AIDS 24(6): 891-897.

10. Shewamene Z, Legesse B, Tsega B, Bhagavathula AS, Endale A (2015) Consistent condom use in HIV/AIDS patients receiving antiretroviral therapy in northwestern Ethiopia: implication to reduce transmission and multiple infections. HIV/AIDS (Auckland, NZ) 7: 119-124.

11. Anene Ak, Ighodaro I, Olufemi IS (2014) The Sexual Behaviours of HIV Positive Patients Receiving Antiretroviral Therapy in HIV Treatment Centre in Nigeria. J AIDS Clin Res 5: 392.

12. (2013) National HIV \& AIDS and Reproductive Health Survey, 2012 (NARHS Plus). Federal Ministry of Health Abuja, Nigeria.

13. Denue BA, Kwayabura SA, Bukbuk D, Inuwa U, Ajayi B B (2014) Evaluation of Condom Use and Associated Factors among Adult HIV clients in Maiduguri, North Eastern Nigeria: A comparative Cross sectional study. World Journal of AIDS 4(2): 169-177.

14. Adebayo AM, Ilesanmi OS, Omotosho BA, Ayodeji 00, Kareem AO, et al. (2014) Disclosure to sexual partner and condom use among HIV positive clients attending ART clinic at a tertiary health facility in South West Nigeria. The Pan African Medical Journal 18: 245.

15. Akinyemi J, Awolude O, Adewole I, Kanki P (2010) Condom use among antiretroviral therapy patients in Ibadan Nigeria. The Journal of infection in Developing countries 4(8): 495-502.

16. (2006) National Population and Housing Census, Federal Republic of Nigeria, National Population Commission. Gazette number 2: 92.

17. Udigwe G, Mbachu I, Onyegbule O, Oguaka V (2014) Use of Condoms among Human Immunodeficiency Virus Positive Women Attending Antenatal Clinic in Nnewi, South East Nigeria. Annals of Medical and Health Sciences Research 4(5): 687-691.

18. Engedashet E, Worku A, Tesfaye G (2014) Unprotected sexual practice and associated factors among People Living with HIV at Ante Retroviral Therapy clinics in Debrezeit Town, Ethiopia: a cross sectional study. Reproductive Health 11: 56

19. Shuper PA, Kiene SM, Mahlase G, Susan MacDonald, Sarah Christie, et al. (2014) HIV Transmission Risk Behavior Among HIV-Positive Patients Receiving Antiretroviral Therapy in KwaZulu-Natal, South Africa. AIDS and behavior 18(8): 1532-1540.

20. Coleman CL, Ball K (2007) Determinants of perceived barriers to condom use among HIV-infected middle-aged and older African-American men. Journal of advanced nursing 60(4): 368-376.

21. Till Bärnighausen, David E Bloom, Salal Humair (2007) Human resources for treating HIV/AIDS: Needs, capacities and gaps. AIDS Patient Care and STDs 21(11): 799-812.

22. Van Damme W, Kober K, Laga M (2006) The real challenges for scaling up ART in sub-Saharan Africa. AIDS 20(5): 653-656. 
23. Ung M, Boateng G, Armah F, Amoyaw J, Luginaah I, et al. (2014) Negotiation for Safer Sex Among Married Women in Cambodia: Role Of Women's Autonomy. Journal of Biosocial Science 46(1): 90-106.

24. Exavery A, Kanté AM, Jackson E, Noronha J, Sikustahili G, et al. (2012) Role of condom negotiation on condom use among women of reproductive age in three districts in Tanzania. BMC Public Health 12(1): 1097.

25. Tobin West C, Maduka O, Onyekwere V, Tella AO (2013) Awareness, acceptability, and use of female condoms among university students in Nigeria: implications for STI/HIV prevention. International Journal of Adolescent Medicine and Health 26(2): 259-265.

26. Peters A, van Driel F, Jansen W (2014) Acceptability of the Female Condom by Sub-Saharan African Women: A Literature Review. African Journal of Reproductive Health 18(4): 34-44.

\section{ISSN: 2574-1241}

DOI: 10.26717/BJSTR.2019.18.003201

Joseph E Enegela. Biomed J Sci \& Tech Res

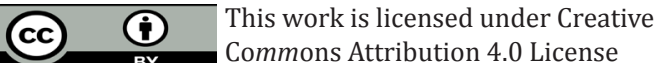

Submission Link: https://biomedres.us/submit-manuscript.php
27. Anglewicz P, Clark S (2013) The Effect of Marriage and HIV Risks on Condom Use Acceptability in Rural Malawi. Social science \& medicine p. 29-40.

28. Dave SS, Stephenson J, Mercey DE, Panahmand N, Jungmann E (2006) Sexual behaviour, condom use, and disclosure of HIV status in HIV infected heterosexual individuals attending an inner London HIV clinic. Sexually Transmitted Infections 82(2): 117-119.

29. Ngure K, Mugo N, Celum C, Baeten JM, Morris M, et al. (2012) A qualitative study of barriers to consistent condom use among HIV-1 sero-discordant couples in Kenya. AIDS Care 24(4): 509-516.

30. Homsy J, Bunnell R, Moore D, Rachel King, Samuel Malamba, et al. (2009) Reproductive Intentions and Outcomes among Women on Antiretroviral Therapy in Rural Uganda: A prospective Cohort Study. PLOS ONE 4(1): e4149.

$\begin{array}{ll}\text { BIOMEDICAL } & \text { Assets of Publishing with us } \\ \text { RESEARCHES } & \text { - Global archiving of articles } \\ & \text { - Immediate, unrestricted online access } \\ \end{array}$

